\title{
Association of Chest CT-Based Quantitative Measures of Muscle and Fat with Post-Lung Transplant Survival and Morbidity: A Single Institutional Retrospective Cohort Study in Korean Population
}

\author{
Young Hoon Cho, MD, $M M^{1}$, Kyung-Hyun Do, MD, $\mathrm{PhD}^{1}$, Eun Jin Chae, $M D, \mathrm{PhD}^{1}$, \\ Se Hoon Choi, MD, PhD², Kyung-Wook Jo, MD, PhD², Sang-Oh Lee, MD, PhD ${ }^{4}$, Sang-Bum Hong, MD, $\mathrm{PhD}^{3}$ \\ ${ }^{1}$ Department of Radiology and Research Institute of Radiology, Asan Medical Center, University of Ulsan College of Medicine, Seoul, Korea; \\ ${ }^{2}$ Department of Thoracic and Cardiovascular Surgery, Asan Medical Center, University of Ulsan College of Medicine, Seoul, Korea; ${ }^{3}$ Division of \\ Pulmonary and Critical Care Medicine, Asan Medical Center, University of Ulsan College of Medicine, Seoul, Korea; ${ }^{4}$ Department of Infectious \\ Disease, Asan Medical Center, University of Ulsan College of Medicine, Seoul, Korea
}

Objective: Abnormal body composition is an important modifiable risk factor in lung transplantation. Therefore, precise quantification of different body components, including muscle and fat, may play an important role in optimizing outcomes in lung transplant patients. The purpose of the study was to investigate the prognostic significance of muscle and subcutaneous fat mass measured on chest CT with regard to lung transplantation survival and other post-transplant outcomes.

Materials and Methods: The study population included 45 consecutive adult lung transplant recipients (mean age of $47.9 \pm$ 12.1 years; 31 males and 14 females) between 2011 and 2017. Preoperative cross-sectional areas of muscle and subcutaneous fat were semi-automatically measured on axial CT images at the level of the 12th thoracic vertebra (T12). Additional normalized indexed parameters, adjusted for either height or weight, were obtained. Associations of quantitative parameters with survival and various other post-transplant outcomes were evaluated.

Results: Of the 45 patients included in the present study, 10 mortalities were observed during the follow-up period. Patients with relative sarcopenia (RS) classified based on height-adjusted muscle area with a cut-off value of $28.07 \mathrm{~cm}^{2} / \mathrm{m}^{2}$ demonstrated worse postoperative survival (log-rank test, $p=0.007$; hazard ratio [HR], 6.39:1) despite being adjusted for age, sex, and body mass index $(H R, 8.58: 1 ; p=0.022)$. Weight-adjusted parameters of muscle area were negatively correlated with duration of ventilator support $(R=-0.54, p<0.001)$ and intensive care unit (ICU) stay $(R=-0.33, p=0.021)$.

Conclusion: Patients with RS demonstrate worse survival after lung transplantation that those without RS. Additionally, quantitative parameters of muscles measured at the T12 level on chest CT were associated with the duration of post-lung transplant ventilator support and duration of stay in the ICU.

Keywords: Lung transplantation; Sarcopenia; Fat; Muscle; Chest CT; Survival

\section{INTRODUCTION}

Since the first reported success in 1983, lung transplantation has been the only available curative treatment option for patients with various end-stage lung diseases (1). More than 50000 lung transplants have been performed worldwide and have been shown to improve life expectancy, level of daily activity, and overall quality of life in advanced chronic lung disease patients (2). In Korea, the first human lung transplantation was performed

Received April 19, 2018; accepted after revision November 11, 2018.

Corresponding author: Kyung-Hyun Do, MD, PhD, Department of Radiology and Research Institute of Radiology, Asan Medical Center, University of Ulsan College of Medicine, 88 Olympic-ro 43-gil, Songpa-gu, Seoul 05505, Korea.

- Tel: (822) 3010-3996•Fax: (822) 2045-4127• E-mail: dokh@amc.seoul.kr

This is an Open Access article distributed under the terms of the Creative Commons Attribution Non-Commercial License (https:// creativecommons.org/licenses/by-nc/4.0) which permits unrestricted non-commercial use, distribution, and reproduction in any medium, provided the original work is properly cited. 
in 1996, and since then, a gradual increase in the number of cases has been observed (3). Although survival after lung transplantation has gradually increased, the procedure, like any other organ transplant surgery, is an invasive modality with relatively high rates of mortality and a reported 5-year survival rate of 54\% (4). Furthermore, there is relative scarcity of lung donors in relation to the constantly increasing number of patients in need of lung transplantation. Particularly, mortality of patients on the waiting list for lung transplantation is reported to be higher in Korea than in western countries (5). Therefore, the identification of potential risk factors and the meticulous selection of transplant candidates are crucial to maximize the benefits and reduce avoidable postoperative morbidity.

Abnormal body composition is an important modifiable risk factor in lung transplantation, with body mass index (BMI) being the most commonly used parameter to characterize body composition in organ transplant candidates (6). However, BMI can neither isolate nor quantify lean muscle and fat mass, and the true significance of BMI on the outcome of lung transplant remains controversial $(7,8)$. Sarcopenia, defined as a loss of skeletal muscle mass and impaired muscle function, is widely known to have negative impact on the treatment outcomes of various diseases, and sarcopenic patients have been reported to have poor survival rates in liver and kidney transplantations $(9,10)$. The majority of lung transplant recipients have also been found to be sarcopenic, and decreased lean muscle mass has been reported to have an association with increased post-transplant morbidity (11-16). Aside from muscle, the abundance or lack of fat tissue is known to have a negative association with various illnesses, including pulmonary diseases; however, its impact on outcome of lung transplantation remains to be clarified $(17,18)$. Therefore, more precise quantification of the different body components, including muscle and fat, may play a role in optimizing treatment outcomes in lung transplant patients.

Among the various modalities, bioelectrical impedance has been the most commonly used tool to assess different body compositions in lung transplant patients because of its robustness and high clinical accessibility (19). However, computed tomography (CT) is currently considered the modality of choice for the evaluation of muscle mass and other body components, as it provides direct visual assessment and improves the reproducibility of measurements (20). The cross-sectional area (CSA) of the muscle at the 3rd lumbar vertebra (L3) level has been found to correlate with total body muscle mass; therefore, it has been used as the reference standard for evaluating sarcopenia in many studies $(21,22)$. However, the L3 level is not routinely visualized in chest CT, which is the standard imaging modality used in preoperative evaluation of lung transplant candidates, and additional abdominal CT scans would result in unnecessary cost and radiation exposure. To overcome such limitations, different methods have been introduced to estimate total body compositions from CT images of the chest; however, the designs and results vary broadly across the published studies (13, 15, 23-25).

The purpose of the present study was to investigate the prognostic significance of muscle and subcutaneous fat mass measured at the 12th thoracic vertebra (T12) level on chest $\mathrm{CT}$ with regard to lung transplantation survival and other post-transplant outcomes.

\section{MATERIALS AND METHODS}

\section{Patients}

The Institutional Review Board approved this retrospective study, and the need for informed consent was waived. By retrospective review of medical records, 51 adult (age $>18$ years) patients who underwent dual lung transplantation at our institution between January 2011 and February 2017 were initially selected for the analysis. Of these 51 patients, concurrent liver transplantation was performed in two patients, and they were excluded from the study. Four additional patients were also excluded because a chest CT scan obtained within 3 months prior to the lung transplantation was not available. Therefore, the final study population consisted of 45 patients (31 male and 14 female patients; mean age, $47.9 \pm 12.1$ years; age range, 20-74 years) (Fig. 1). By institutional policy, all recipients underwent respiratory rehabilitation after the completion of lung transplantation.

Individual preoperative demographic data including age, sex, weight, and height were collected for each patient. After the lung transplantation, information regarding survival, duration of ventilator support, duration of stay in the intensive care unit (ICU), and duration of hospital stay (HOD) were documented as the primary/secondary outcomes of the current study. All included lung transplant recipients were routinely followed up for survival analyses. 


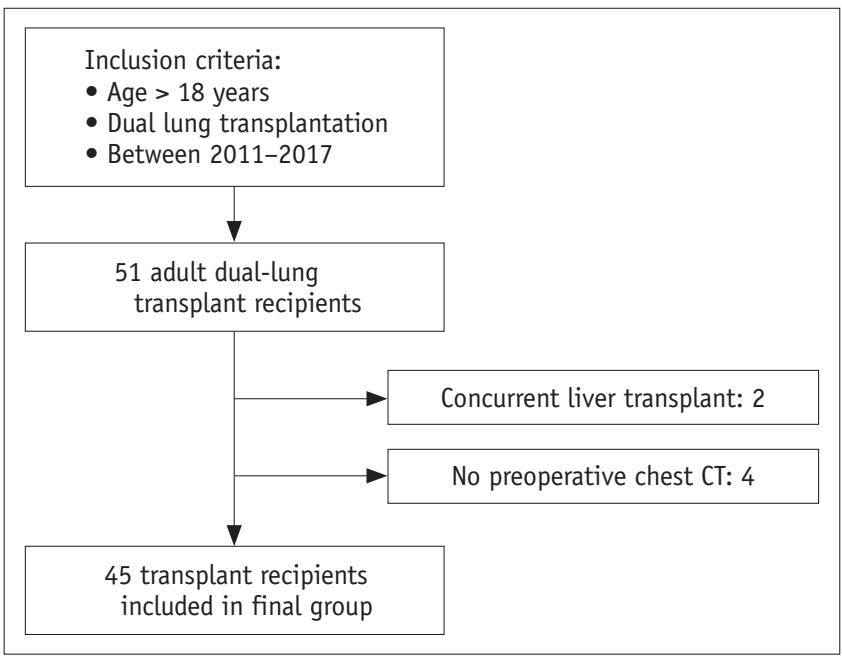

Fig. 1. Flow diagram of study population. Final study population included 45 adult lung transplantation recipients from 2011 to 2017. $\mathrm{CT}=$ computed tomography

\section{СT Image Evaluation}

All chest $\mathrm{CT}$ examinations were performed in a

caudocranial direction with patients in the supine position, using one of the three available multidetector CT scanners in our institution (Somatom Sensation, Somatom definition, Somatom definition AS; Siemens Healthineers, Forchheim, Germany). Tube voltage was set at $120 \mathrm{kV}$ with beam collimation at $0.6-0.75 \mathrm{~mm}$ and a pitch of 1 . Chest CT images were reconstructed at various slice thicknesses and intervals; however, for the body composition analysis, images reconstructed at 5 -mm slice thickness and intervals using a B50 kernel algorithm were selected.

A board-certified radiologist with 8 years of experience performed the quantitative evaluations. The reader was blinded to the demographic records, medical histories, and postoperative outcomes of the patient. Cross-sectional total muscle area (TMA) and subcutaneous fat area (SFA) were measured on a single-slice axial CT image at the level of the T12, which was visualized in all routine preoperative chest CT examinations. After manual selection of the appropriate slice-level, the visceral organs and central spinal canal were semi-automatically removed from the region of interest using dedicated in-house software. TMA and SFA were then automatically computed using predefined CT Hounsfield unit (HU) thresholds: muscle, -29 to $150 \mathrm{HU}$; subcutaneous fat, -190 to $-30 \mathrm{HU}$ (Fig. 2). In addition to raw measurements, normalized indexed values for TMA and SFA adjusted for either height (muscle-height index [MHI] and fat-height index [FHI] in $\mathrm{cm}^{2} / \mathrm{m}^{2}$ ) or weight (muscleweight index [MWI] and fat-weight index [FWI] in $\mathrm{cm}^{2} / \mathrm{kg}$ )

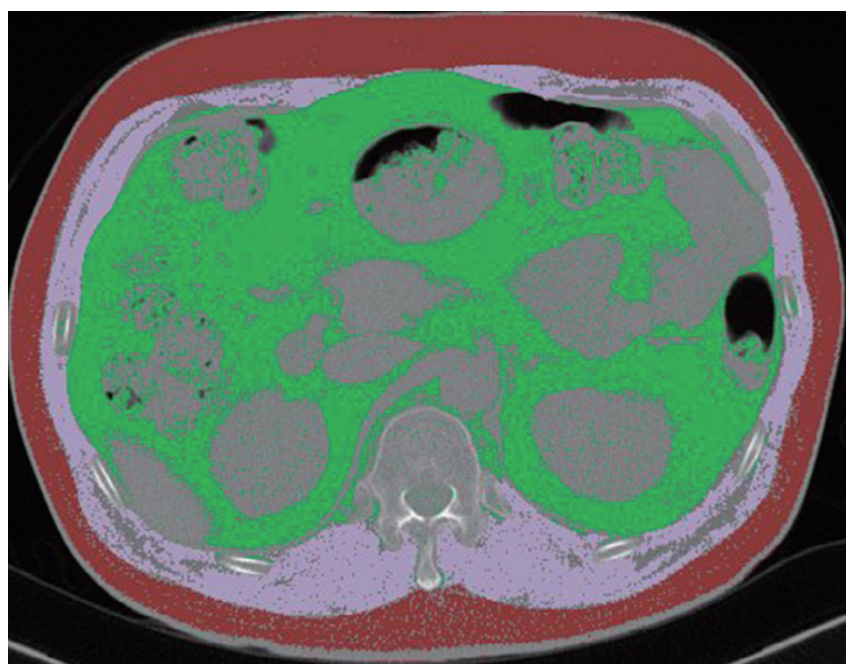

Fig. 2. Example of cross-sectional area measurement at level of 12th thoracic vertebra. Cross-sectional total muscle area (pink) and subcutaneous fat area (red) were automatically calculated using predefined CT HU thresholds (muscle, -29 to $150 \mathrm{HU}$; subcutaneous fat, -190 to $-30 \mathrm{HU})$. $\mathrm{HU}=$ Hounsfield unit

were calculated (26).

\section{Statistical Analyses}

Continuous variables were expressed as mean and standard deviation. Independent $t$ tests and chi-square tests were performed to assess differences in patient characteristics between groups. The survival study was performed using a Kaplan-Meier estimate and Cox-regression analysis. Correlation analyses between the measured body composition parameters and various post-transplant outcomes were evaluated with Pearson's correlation coefficient. All statistical analyses were performed with SPSS version 21.0 (IBM Corp., Armonk, NY, USA), and $p$ values $<0.05$ were considered significant.

\section{RESULTS}

\section{Characteristics of the Study Population}

A total of 45 lung transplant recipients were included in the study, and their baseline characteristics are summarized in Table 1. The mean BMI value of the total study population was $22.3 \pm 3.9 \mathrm{~kg} / \mathrm{m}^{2}$. Vast majority of the recipients were within normal or underweight range, and only one patient demonstrated BMI value greater than 30 $\mathrm{kg} / \mathrm{m}^{2}$. Among the included patients, idiopathic pulmonary fibrosis (IPF) in 26 (57\%), interstitial lung disease other than IPF in 10, bronchiolitis obliterans in 5 , and other causes of respiratory failures in 4 patients were identified 
Table 1. General Characteristics and Measured Parameters of Patients

\begin{tabular}{|c|c|c|c|c|}
\hline \multirow{2}{*}{ Parameters } & \multirow{2}{*}{$\begin{array}{l}\text { Total Population } \\
\qquad(n=45)\end{array}$} & \multicolumn{2}{|c|}{ Mortality } & \multirow{2}{*}{$P$} \\
\hline & & Yes $(n=10)$ & No $(n=35)$ & \\
\hline Age & $47.9 \pm 12.1$ & $43.9 \pm 14.6$ & $48.3 \pm 11.5$ & 0.322 \\
\hline Sex & & & & 0.142 \\
\hline Male & 31 & 5 & 26 & \\
\hline Female & 14 & 5 & 9 & \\
\hline Weight (kg) & $61.6 \pm 11.5$ & $60.0 \pm 14.0$ & $62.1 \pm 11.1$ & 0.629 \\
\hline Height (cm) & $165.8 \pm 6.6$ & $165.5 \pm 5.6$ & $166.2 \pm 6.9$ & 0.779 \\
\hline BMI $\left(\mathrm{kg} / \mathrm{m}^{2}\right)$ & $22.3 \pm 3.9$ & $21.8 \pm 5.1$ & $22.5 \pm 3.7$ & 0.682 \\
\hline Preoperative diagnosis & & & & 0.778 \\
\hline IPF & 26 & 5 & 21 & \\
\hline Other ILD & 10 & 2 & 8 & \\
\hline $\mathrm{B} 0$ & 5 & 2 & 3 & \\
\hline Others & 4 & 1 & 3 & \\
\hline Ventilator days & $14.9 \pm 21.0$ & $53.0 \pm 50.1$ & $10.8 \pm 11.1$ & 0.019 \\
\hline ICU days & $22.2 \pm 29.0$ & $59.2 \pm 52.7$ & $16.8 \pm 12.8$ & 0.017 \\
\hline Hospital stay (days) & $89.4 \pm 91.3$ & $78.8 \pm 51.2$ & $94.3 \pm 43.2$ & 0.672 \\
\hline Muscle area $\left(\mathrm{cm}^{2}\right)$ & $80.5 \pm 17.6$ & $71.6 \pm 16.5$ & $83.1 \pm 17.5$ & 0.072 \\
\hline Fat area $\left(\mathrm{cm}^{2}\right)$ & $65.9 \pm 37.3$ & $74.9 \pm 48.2$ & $62.3 \pm 31.6$ & 0.264 \\
\hline $\operatorname{MHI}\left(\mathrm{cm}^{2} / \mathrm{m}^{2}\right)$ & $29.1 \pm 5.8$ & $26.0 \pm 5.1$ & $30.1 \pm 4.9$ & 0.042 \\
\hline MWI $\left(\mathrm{cm}^{2} / \mathrm{kg}\right)$ & $1.3 \pm 0.2$ & $1.2 \pm 0.3$ & $1.3 \pm 0.2$ & 0.102 \\
\hline FHI $\left(\mathrm{cm}^{2} / \mathrm{m}^{2}\right)$ & $24.5 \pm 15.7$ & $28.8 \pm 9.2$ & $23.1 \pm 11.2$ & 0.308 \\
\hline FWI $\left(\mathrm{cm}^{2} / \mathrm{kg}\right)$ & $1.0 \pm 0.5$ & $1.2 \pm 0.7$ & $1.0 \pm 0.5$ & 0.196 \\
\hline
\end{tabular}

$\mathrm{BMI}=$ body mass index, $\mathrm{BO}=$ bronchiolitis obliterans, $\mathrm{FHI}=$ fat-height index, FWI = fat-weight index, ICU days = duration of stay in intensive care unit in days, ILD = interstitial lung disease, IPF = idiopathic pulmonary fibrosis, MHI = muscle-height index, MWI = muscle-weight index, Ventilator days = duration of ventilator support in days

as the preoperative diagnoses.

\section{Post-Transplant Survival}

Median follow-up period for all recipients was 32 months (range, 7-76 months), and overall mortality was $22.2 \%$. Infections, such as pneumonia, was the most common cause of mortality (6 of 10 cases), followed by three cases of mortality due to shock and multiple organ failure. In one patient, the cause of death was not clearly identified. There were no significant differences in age, sex, weight, BMI, and preoperative diagnosis between the survivors and the non-survivors (Table 1). Among the measured quantitative parameters, only MHI was significantly different between the survivors and the non-survivors (mean MHI; 26.0 and 30.1 , respectively, $p=0.042$ ). For subgroup analysis, 18 (40\%) patients with MHI values less than a cut-off value of $28.07 \mathrm{~cm}^{2} / \mathrm{m}^{2}$, set to yield the greatest difference in survival, were classified as patients with relative sarcopenia (RS) (27). Patients with RS were younger, were more likely to be female, weighed less, and had lower value of BMI, but no difference was noted in preoperative diagnoses
(Table 2). Of the 10 total mortalities, eight occurred in the RS group and only two occurred in the non-RS group. On Kaplan-Meier survival analysis, patients in the RS group had significantly worse overall survival (log-rank test, $p=0.007$ ) (Fig. 3). The relative hazard ratio (HR) estimated using univariate Cox-regression analysis was 6.39:1 $(p=0.019)$ for the RS group (Table 3). Presence of RS was observed to be a significant predictor of increased post-transplant mortality (HR, 8.58:1, $p=0.022$ ) despite adjustments for age, sex, and BMI. None of the other parameters, including sex, age, BMI, TMA, SFA, and other normalized indices were found to have a significant influence on post-lung transplant survival.

\section{Associations with Other Post-Transplant Outcomes}

Results from the correlation study revealed that MWI had a significant negative correlation with the duration of ventilator support $(R=-0.54, p<0.001)$ and ICU stay $(R=-0.33, p$ $=0.021$ ) (Table 4). For the MHI, a significant but weaker negative correlation was noted only with the duration of ventilator support $(R=-0.33, p=0.021)$. No significant 
associations were observed between the parameters of fat measurement, FHI and FWI, and postoperative morbidities.

\section{DISCUSSION}

The current study is one of the earliest to report that a quantitative measure of muscle area on $\mathrm{CT}$ is associated with lung transplant survival. Although limited by a small number of study subjects, patients who were relatively sarcopenic were shown to have poorer survival rates after lung transplantation, with the Cox proportional HR being 8.58:1 even after adjustments were made for age, sex, and BMI of the recipient.

Sarcopenia has been established as an important

Table 2. Characteristics of Patients with RS

\begin{tabular}{|c|c|c|c|}
\hline \multirow{2}{*}{ Parameters } & \multicolumn{2}{|c|}{ Relative Sarcopenia* } & \multirow{2}{*}{$P$} \\
\hline & Yes $(n=18)$ & No $(n=27)$ & \\
\hline Age & $43.5 \pm 13.6$ & $50.6 \pm 10.3$ & 0.030 \\
\hline Sex & & & 0.012 \\
\hline Male & 8 & 23 & \\
\hline Female & 10 & 4 & \\
\hline Weight (kg) & $54.6 \pm 11.1$ & $66.2 \pm 9.7$ & 0.001 \\
\hline Height (cm) & $166.1 \pm 6.8$ & $166.0 \pm 6.6$ & 0.960 \\
\hline BMI $\left(\mathrm{kg} / \mathrm{m}^{2}\right)$ & $19.8 \pm 4.1$ & $23.9 \pm 2.8$ & 0.001 \\
\hline Preoperative diagnosis & & & 0.394 \\
\hline IPF & 9 & 17 & \\
\hline Other ILD & 4 & 6 & \\
\hline BO & 4 & 1 & \\
\hline Others & 2 & 2 & \\
\hline Mortality & $8(44.4 \%)$ & $2(7.4 \%)$ & 0.005 \\
\hline Ventilator days & $35.7 \pm 28$ & $9.7 \pm 9.3$ & 0.041 \\
\hline ICU days & $43.2 \pm 39.4$ & $14.9 \pm 10.5$ & 0.032 \\
\hline Hospital stay (days) & $94.8 \pm 52.5$ & $88.0 \pm 41.1$ & 0.810 \\
\hline Muscle area $\left(\mathrm{cm}^{2}\right)$ & $63.9 \pm 9.5$ & $91.5 \pm 12.3$ & $<0.001$ \\
\hline Fat area $\left(\mathrm{cm}^{2}\right)$ & $61.5 \pm 44.3$ & $68.8 \pm 31.6$ & 0.580 \\
\hline MHI $\left(\mathrm{cm}^{2} / \mathrm{m}^{2}\right)$ & $22.1 \pm 2.9$ & $33.0 \pm 3.1$ & $<0.001$ \\
\hline MWI $\left(\mathrm{cm}^{2} / \mathrm{kg}\right)$ & $1.2 \pm 0.2$ & $1.4 \pm 0.2$ & 0.002 \\
\hline $\mathrm{FHI}\left(\mathrm{cm}^{2} / \mathrm{m}^{2}\right)$ & $22.4 \pm 17.2$ & $26.4 \pm 14.4$ & 0.412 \\
\hline FWI $\left(\mathrm{cm}^{2} / \mathrm{kg}\right)$ & $1.0 \pm 0.7$ & $1.0 \pm 0.1$ & 0.934 \\
\hline
\end{tabular}

*Patients with MHI value less than $28.07 \mathrm{~cm}^{2} / \mathrm{m}^{2}$. RS = relative sarcopenia risk factor for mortality in various medical and surgical conditions $(22,28)$. In this context, several individual studies have reported that muscle parameters analyzed using CT images had significant associations with postoperative mortality and morbidity in liver transplantation surgeries (29-31). Kelm et al. (32) reported worse survival after lung transplantation in patients with

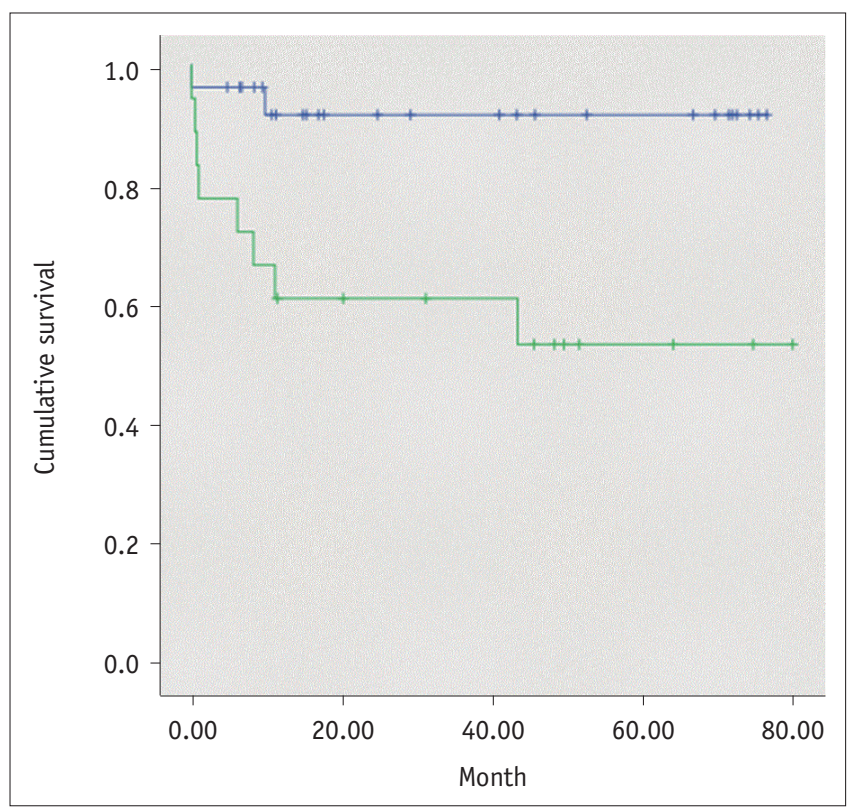

Fig. 3. Post-transplantation survival analysis. Patients with relative sarcopenia were associated with worse overall survival (green line) (log-rank test, $p=0.007)$. Relative hazard ratio estimated using Cox-regression analysis was 6.39:1 $(p=0.019)$ for univariate and 8.58:1 $(p=0.022)$ for multivariate analysis, adjusted for recipient's age, sex, and body mass index.

Table 4. Association of Quantitative Parameters with Post-Lung Transplantation Morbidity

\begin{tabular}{lcccrr}
\hline \multirow{2}{*}{ Parameters } & \multicolumn{2}{c}{ ICU Days } & & \multicolumn{2}{c}{ Vent Days } \\
\cline { 2 - 3 } \cline { 5 - 6 } & $R$ & $P$ & & $R$ & \multicolumn{1}{c}{$P$} \\
\hline MHI & -0.24 & 0.111 & & -0.33 & 0.021 \\
MWI & -0.33 & 0.021 & & -0.54 & $<0.001$ \\
FHI & 0.29 & 0.852 & & 0.18 & 0.211 \\
FWI & 0.46 & 0.763 & & 0.17 & 0.263 \\
\hline
\end{tabular}

$R=$ correlation coefficients

Table 3. Results of Cox Regression Analysis

\begin{tabular}{|c|c|c|c|c|c|c|c|c|}
\hline \multirow{2}{*}{ Parameters } & \multicolumn{3}{|c|}{ Univariate Analysis } & \multirow{2}{*}{$P$} & \multicolumn{3}{|c|}{ Multivariate Analysis } & \multirow{2}{*}{$P$} \\
\hline & HR & & & & $\mathrm{HR}$ & & & \\
\hline RS & 6.39 & 1.36 & 30.2 & 0.019 & 8.58 & 1.36 & 54.1 & 0.022 \\
\hline Age & 0.98 & 0.93 & 10.3 & 0.413 & 0.99 & 0.95 & 1.05 & 0.953 \\
\hline Sex & 0.45 & 0.128 & 1.53 & 0.442 & 0.89 & 0.89 & 4.16 & 0.885 \\
\hline BMI & 0.97 & 0.83 & 1.13 & 0.665 & 1.07 & 0.91 & 1.27 & 0.379 \\
\hline
\end{tabular}

$\mathrm{CI}=$ confidence interval, $\mathrm{HR}=$ hazard ratio 
decreased muscle index; however, abdominal CT image at the 2 nd and 3rd lumbar interface was used for the measurement. Another study measured core muscle CSA on abdominal CT images and used it as an indicator of sarcopenia; however, no significant influence was observed on post-lung transplant mortalities (33). Two prior studies utilized chest $\mathrm{CT}$ to measure the TMA of the thoracic muscle at the level of the carina in lung transplantation recipients, but no significant association between sarcopenia and decreased survival was noted $(13,15)$. In the present study, MHI was measured at the T12 level on chest CT images and was found to be a significant prognostic factor for survival in lung transplantation recipients in Korea. The discrepancy in results may be due to the use of different methods for measuring muscle characteristics and the dissimilarity in demographic features, legal policies, and patient selection protocols in Korean lung transplantation recipients. For example, Korean recipients are more likely to have IPF as the underlying pulmonary disease, be less obese, and have poorer preoperative medical condition compared with North American patients (34).

Currently, the most commonly used standard level for CT-based estimation of body composition is the L3 because TMA and fat tissue volume measured at this level demonstrated good correlation with total body skeletal muscle and fat tissue volumes $(35,36)$. However, the $L 3$ level is not routinely visualized in the scan range of the chest $\mathrm{CT}$, which is the gold standard imaging method for preoperative evaluation of lung transplant candidates. As an additional abdominal CT examination may result in unnecessary radiation exposure and increased cost, it would be in the best interest of the patient to assess body composition on chest CT images. In one study, this issue was addressed by using chest CT to measure the CSA of muscle at the 1st lumbar vertebra (L1) level in Korean lung cancer patients, and a high correlation was observed with values measured at the L3 level (23). Unfortunately, due to variations in the inspiration status of patients and institutional CT protocols, the L1 level may not be completely included within the chest CT scan range, which was true for 11 of the 45 patients included in the present study (37). In another study, authors reported that TMA at both the 7th thoracic vertebra (T7) and T12 levels correlated with results at the L3 level; however, a significantly stronger association was observed at the T12 level (24). Based on this finding and the fact that the T12 level was always scanned in each chest CT, evaluations of muscle and subcutaneous fat were performed using axial CT images at the T12 level in the present study.

Nemec et al. (24) suggested a cut-off value for sarcopenia measured on axial CT images at the T12 level; however, direct application of this value to the subjects included in the present study would have been inappropriate due to differences in ethnicity, underlying illness, and other diverse patient demographic features. More importantly, there is currently no consensus on standard measurement methods or reference values for defining sarcopenia on CT (24). Therefore, patients in the present study were divided into two subgroups using a cut-off MHI value of 28.07 $\mathrm{cm}^{2} / \mathrm{m}^{2}$. Such a cut-off value was selected to yield the greatest survival difference between the two groups, while minimizing bias and maintaining a sufficient number of patients within each subgroup for statistical assessment. Establishing a generalized sex-specific threshold for sarcopenia would have been inappropriate, owing to the small number of patients included in the present study. Further studies with larger number of patients are required to determine the possible cut-off value for the diagnosis of sarcopenia in Korean population.

Both height- and weight-adjusted TMA were found to be associated with decreased duration of postoperative ventilator support ( $R=-0.33, R=-0.54$, respectively); however, only MWI was also associated with reduced duration of stay in the ICU $(R=-0.33)$. No significant correlation was noted with HOD. SFA and its adjusted indices were not associated with duration of either ventilator or ICU care. Association of abdominal CTbased muscle parameters with duration of ventilator care and ICU stay has been reported in both lung and liver transplantation recipients $(30,33)$. However, no significant association has been reported with a chest CT-based muscle index prior to the present study. Positive results from the current study and prior reports suggest that quantitative parameters of muscles measured on CT images are predictors of postoperative recovery, such as ventilation support and overall period of stay in the ICU, after lung transplantation.

Between the two normalized muscle indices, MWI exhibited a higher correlation with short-term posttransplant recovery. Although the height of the patient in meters squared has most commonly been used to normalize measured muscle or fat areas in CT-based studies, there is currently no gold standard formula for calculating the normalized index values. Height- and weight-adjusted body composition indices have been used in various studies, with 
both being reported to have significant associations with diverse individual clinical parameters $(20,38)$. One study conducted on a large number of Korean patients reported that the weight-adjusted parameter of the muscle mass of a patient was a more powerful risk factor for development of metabolic syndrome than the height-adjusted parameter (39). Therefore, determination of the optimal quantitative parameter to predict postoperative morbidity requires further evaluation.

Although BMI is the most widely used parameter to determine body composition in organ transplantation candidates, BMI was not found to be associated with survival or any other evaluated postoperative outcome measures in the current analysis (8). Furthermore, association with survival or duration of postoperative care was not observed with quantitative measurements of subcutaneous fat. Therefore, there may be benefit in separately quantifying body components, especially muscles, instead of using BMI as a prognostic index for selection of candidates and anticipation of postoperative outcome.

Several limitations must be acknowledged in the present study. The first limitation is the small number of patients included, which markedly restricted the ability to perform more flexible subgrouping and reduced the power of the statistical analyses. However, due to the restricted exclusion criteria, all but 6 of the 51 adult lung transplants performed in our institution during the six-year period were included in the current study, and the influence of selection bias would have been weakened. Second, this was a retrospective single-center study. Quantitative muscle and subcutaneous fat measurements were performed during the preoperative period, and longitudinal changes in body composition could not be evaluated. Therefore, alterations in body composition during the ICU care and long-term post-transplant recovery could not be assessed. For the purpose of survival analysis, the study population was divided into two groups based on the value of MHI, and sex-specific cut-off values for sarcopenia or adipopenia were not evaluated in the present study. One previous study proposed possible cut-off values for sarcopenia measured at the T12 level on chest CT; however, the study was based on a non-Asian population with cardiovascular disease and the authors used reference values obtained from elderly oncological patients (24). Therefore, direct application of such cut-off values to the current study population, which exclusively comprised Asian patients with end-stage lung disease, would have been unsuitable. Although the cut-off value adopted in the present study cannot be applied to the general population, the value was sufficient to assess the influence of being relatively sarcopenic on survival after lung transplantation, in a small number of patients. Future studies with a larger sample size are warranted. An additional limitation of the present study is the fact that only subcutaneous fat, and not visceral fat, was analyzed. Finally, transplant candidates did not undergo examinations for muscular function, and its relative importance with regard to lung transplantation outcomes, in comparison with muscle mass, was not evaluated.

In conclusion, patients with a relatively smaller value of height-adjusted muscle area (cut-off value, $28.07 \mathrm{~cm}^{2} / \mathrm{m}^{2}$ ) quantitatively measured using chest CT were associated with inferior survival after lung transplantation in both univariate and multivariate analyses. Additionally, post-lung transplant duration of ventilator support and duration of ICU stay were relatively shortened in patients with greater value of chest CT-measured muscle parameters. Further research is necessary to establish a sex-specific threshold for sarcopenia, to evaluate longitudinal changes in body composition, and validate their prognostic significance in larger, more diverse study populations.

\section{Conflicts of Interest}

The authors have no potential conflicts of interest to disclose.

\section{ORCID iDs}

Kyung-Hyun Do

https://orcid.org/0000-0003-1922-4680

Young Hoon Cho

https://orcid.org/0000-0002-9925-7468

\section{REFERENCES}

1. Toronto Lung Transplant Group. Unilateral lung transplantation for pulmonary fibrosis. N Engl J Med 1986;314:1140-1145

2. Yusen RD, Edwards LB, Kucheryavaya AY, Benden C, Dipchand AI, Goldfarb SB, et al. The registry of the International Society for Heart and Lung Transplantation: thirtysecond official adult lung and heart-lung transplantation report--2015; Focus theme: early graft failure. J Heart Lung Transplant 2015;34:1264-1277

3. Haam SJ, Lee DY, Paik HC. An overview of lung transplantation in Korea. Transplant Proc 2008;40:2620-2622

4. Thabut G, Mal H. Outcomes after lung transplantation. J Thorac Dis 2017;9:2684-2691 
5. Paik HC, Haam SJ, Lee DY, Yi GJ, Song SW, Kim YT, et al. The fate of patients on the waiting list for lung transplantation in Korea. Transplant Proc 2012;44:865-869

6. Egan TM, Murray S, Bustami RT, Shearon TH, McCullough KP, Edwards LB, et al. Development of the new lung allocation system in the United States. Am J Transplant 2006;6(5 Pt 2):1212-1227

7. Madill J, Gutierrez C, Grossman J, Allard J, Chan C, Hutcheon $M$, et al. Nutritional assessment of the lung transplant patient: body mass index as a predictor of 90-day mortality following transplantation. J Heart Lung Transplant 2001;20:288-296

8. Singer JP, Peterson ER, Snyder ME, Katz PP, Golden JA, D'Ovidio $F$, et al. Body composition and mortality after adult lung transplantation in the United States. Am J Respir Crit Care Med 2014;190:1012-1021

9. Englesbe MJ, Patel SP, He K, Lynch RJ, Schaubel DE, Harbaugh C, et al. Sarcopenia and mortality after liver transplantation. J Am Coll Surg 2010;211:271-278

10. Streja E, Molnar MZ, Kovesdy CP, Bunnapradist S, Jing J, Nissenson AR, et al. Associations of pretransplant weight and muscle mass with mortality in renal transplant recipients. Clin J Am Soc Nephrol 2011;6:1463-1473

11. Hook JL, Lederer DJ. Selecting lung transplant candidates: where do current guidelines fall short? Expert Rev Respir Med 2012;6:51-61

12. Kyle UG, Nicod L, Romand JA, Slosman D0, Spiliopoulos A, Pichard C. Four-year follow-up of body compostion in lung transplant patients. Transplantation 2003;75:821-828

13. Lee S, Paik HC, Haam SJ, Lee CY, Nam KS, Jung HS, et al. Sarcopenia of thoracic muscle mass is not a risk factor for survival in lung transplant recipients. $J$ Thorac Dis 2016;8:2011-2017

14. Maury G, Langer D, Verleden G, Dupont L, Gosselink R, Decramer $M$, et al. Skeletal muscle force and functional exercise tolerance before and after lung transplantation: a cohort study. Am J Transplant 2008;8:1275-1281

15. Rozenberg D, Mathur S, Herridge M, Goldstein R, Schmidt $\mathrm{H}$, Chowdhury NA, et al. Thoracic muscle cross-sectional area is associated with hospital length of stay post lung transplantation: a retrospective cohort study. Transpl Int 2017;30:713-724

16. Rozenberg D, Wickerson L, Singer LG, Mathur S. Sarcopenia in lung transplantation: a systematic review. J Heart Lung Transplant 2014;33:1203-1212

17. Camus V, Lanic H, Kraut J, Modzelewski R, Clatot F, Picquenot JM, et al. Prognostic impact of fat tissue loss and cachexia assessed by computed tomography scan in elderly patients with diffuse large B-cell lymphoma treated with immunochemotherapy. Eur J Haematol 2014;93:9-18

18. Lee SJ, Ryu YJ, Lee JH, Chang JH, Shim SS. The impact of low subcutaneous fat in patients with nontuberculous mycobacterial lung disease. Lung 2014;192:395-401

19. Kyle UG, Genton L, Mentha G, Nicod L, Slosman D0, Pichard
C. Reliable bioelectrical impedance analysis estimate of fatfree mass in liver, lung, and heart transplant patients. JPEN J Parenter Enteral Nutr 2001;25:45-51

20. Cruz-Jentoft AJ, Baeyens JP, Bauer JM, Boirie Y, Cederholm T, Landi F, et al. Sarcopenia: European consensus on definition and diagnosis: report of the European Working Group on sarcopenia in older people. Age Ageing 2010;39:412-423

21. Mourtzakis M, Prado CM, Lieffers JR, Reiman T, McCargar LJ, Baracos VE. A practical and precise approach to quantification of body composition in cancer patients using computed tomography images acquired during routine care. Appl Physiol Nutr Metab 2008;33:997-1006

22. Pamoukdjian F, Bouillet T, Lévy V, Soussan M, Zelek L, Paillaud E. Prevalence and predictive value of pre-therapeutic sarcopenia in cancer patients: a systematic review. Clin Nutr 2018;37:1101-1113

23. Kim EY, Kim YS, Park I, Ahn HK, Cho EK, Jeong YM, et al. Evaluation of sarcopenia in small-cell lung cancer patients by routine chest CT. Support Care Cancer 2016;24:4721-4726

24. Nemec U, Heidinger B, Sokas C, Chu L, Eisenberg RL. Diagnosing sarcopenia on thoracic computed tomography: quantitative assessment of skeletal muscle mass in patients undergoing transcatheter aortic valve replacement. Acad Radiol 2017;24:1154-1161

25. Tong Y, Udupa JK, Torigian DA, Odhner D, Wu C, Pednekar G, et al. Chest fat quantification via CT based on standardized anatomy space in adult lung transplant candidates. PLoS One 2017;12:e0168932

26. Meng NH, Li CI, Liu CS, Lin WY, Lin CH, Chang CK, et al. Sarcopenia defined by combining height- and weight-adjusted skeletal muscle indices is closely associated with poor physical performance. J Aging Phys Act 2015;23:597-606

27. Budczies J, Klauschen F, Sinn BV, Györffy B, Schmitt WD, Darb-Esfahani S, et al. Cutoff Finder: a comprehensive and straightforward Web application enabling rapid biomarker cutoff optimization. PLoS One 2012;7:e51862

28. Malietzis G, Aziz 0, Bagnall NM, Johns N, Fearon KC, Jenkins JT. The role of body composition evaluation by computerized tomography in determining colorectal cancer treatment outcomes: a systematic review. Eur J Surg Oncol 2015;41:186196

29. Cruz RJ Jr, Dew MA, Myaskovsky L, Goodpaster B, Fox K, Fontes $\mathrm{P}$, et al. Objective radiologic assessment of body composition in patients with end-stage liver disease: going beyond the BMI. Transplantation 2013;95:617-622

30. DiMartini A, Cruz RJ Jr, Dew MA, Myaskovsky L, Goodpaster $B$, Fox $K$, et al. Muscle mass predicts outcomes following liver transplantation. Liver Transpl 2013;19:1172-1180

31. Krell RW, Kaul DR, Martin AR, Englesbe MJ, Sonnenday CJ, Cai S, et al. Association between sarcopenia and the risk of serious infection among adults undergoing liver transplantation. Liver Transpl 2013;19:1396-1402

32. Kelm DJ, Bonnes SL, Jensen MD, Eiken PW, Hathcock MA, Kremers WK, et al. Pre-transplant wasting (as measured 
by muscle index) is a novel prognostic indicator in lung transplantation. Clin Transplant 2016;30:247-255

33. Weig T, Milger K, Langhans B, Janitza S, Sisic A, Kenn K, et al. Core muscle size predicts postoperative outcome in lung transplant candidates. Ann Thorac Surg 2016;101:1318-1325

34. Jeong YH, Choi S, Park SI, Kim DK; Asan Medical Center Lung Transplantation Team. Clinical outcomes of lung transplantation: experience at Asan Medical Center. Korean J Thorac Cardiovasc Surg 2018;51:22-28

35. Prado CM, Lieffers JR, McCargar LJ, Reiman T, Sawyer MB, Martin L, et al. Prevalence and clinical implications of sarcopenic obesity in patients with solid tumours of the respiratory and gastrointestinal tracts: a population-based study. Lancet Oncol 2008;9:629-635

36. Shen W, Punyanitya M, Wang Z, Gallagher D, St-Onge MP,
Albu J, et al. Total body skeletal muscle and adipose tissue volumes: estimation from a single abdominal cross-sectional image. J Appl Physiol (1985) 2004;97:2333-2338

37. Oh JK, Ahn MI, Kim HL, Park SH, Shin E. Retrodiaphragmatic portion of the lung: how deep is the posterior costophrenic sulcus on posteroanterior chest radiography? Clin Radiol 2009;64:786-791

38. Furushima T, Miyachi M, Iemitsu M, Murakami H, Kawano H, Gando $Y$, et al. Comparison between clinical significance of height-adjusted and weight-adjusted appendicular skeletal muscle mass. J Physiol Anthropol 2017;36:15

39. Lim S, Kim JH, Yoon JW, Kang SM, Choi SH, Park YJ, et al. Sarcopenic obesity: prevalence and association with metabolic syndrome in the Korean Longitudinal Study on Health and Aging (KLoSHA). Diabetes Care 2010;33:1652-1654 